Ibáñez Llácer, José Vicente. La industria del siglo XXI: el caso de Alcoy (Alicante). GeoGraphos. [En línea]. Alicante: Grupo Interdisciplinario de Estudios Críticos y de América Latina (GIECRYAL) de la Universidad de Alicante, 14 de febrero de 2013, vol. 4, no 40, p. 195-222 [ISSN: 2173-1276].

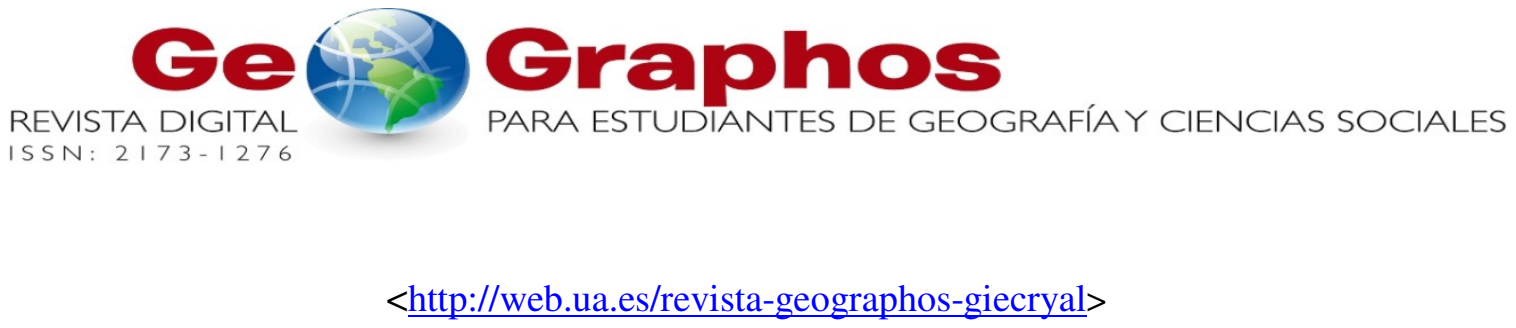

Vol. 4. No 40

Año 2013

\title{
LA INDUSTRIA DEL SIGLO XXI: EL CASO DE ALCOY (ALICANTE)
}

\author{
José Vicente Ibáñez Llácer \\ Estudiante de la Licenciatura de Geografía. Universidad de Alicante (Alicante, España) \\ Correo electrónico: josevi-alcoy90@ hotmail.com
}

Recibido: 2 de junio de 2012. Devuelto para revisión: 14 de octubre de 2012. Aceptado: 14 de febrero de 2013

\section{RESUMEN}

Los nuevos espacios industriales del nuevo siglo basados en las nuevas tecnologías y en la innovación, y su posible implantación en la ciudad de Alcoy con el objetivo de impulsar el desarrollo en la ciudad y poner fin al estancamiento económico y demográfico que ha sufrido en los últimos años como consecuencia de la incompetencia de los políticos que la han gobernado y que no han sabido crear ni un metro cuadrado de suelo industrial provocando la marcha de muchas empresas a las localidades vecinas, todo ello teniendo en cuenta las limitaciones que impone un medio natural privilegiado y que cabe proteger entre todos.

Palabras clave: Espacios industriales, nuevas tecnologías, innovación, Alcoy.

\section{THE INDUSTRY OF XXI CENTURY: THE CASE OF ALCOY (ALICANTE)}

\section{ABSTRACT}

The new industrial spaces of the new century based on the new technologies and on the innovation, and his possible development in Alcoy's city with the aim to stimulate the 
development in the city and to put end to the economic and demographic stagnation that has suffered in the last years as consequence of the incompetence of the politicians who have governed it and who have could create not even a square meter of industrial soil provoking the march of many companies to the neighboring localities, all this having in it counts the limitations that a half privileged native imposes and that it is necessary to protect between all.

Key words: Industrial Spaces, New Technologies, Innovation, City of Alcoy.

\section{INDUSTRIA DO SÉCULO XXI: O CASO DO ALCOY (ALICANTE)}

\section{RESUMO}

Os novos espaços industriais do novo século, com base em novas tecnologias e inovação e seu possível desenvolvimento na cidade de Alcoy, a fim de promover o desenvolvimento da cidade e acabar com a estagnação econômica e da população que tem sofrido nos últimos anos como resultado da incompetência dos políticos que têm governado e que não tenham sido capazes de criar até mesmo um metro quadrado de terreno industrial ocasionando a saída de muitas empresas para cidades vizinhas, tudo tendo em conta as limitações de um ambiente natural privilegiado e a ser protegida em conjunto.

Palavras-chave: Espaços industriais, novas tecnologias, inovação, cidade de Alcoy.

\section{INTRODUCCIÓN}

El estudio de la actividad industrial es una de las corrientes con mayor tradición en la Geografía Humana. Destaca la importancia de la industria como motor de transformación de las estructuras espaciales, como agente principal de las dinámicas territoriales en un país fuertemente industrializado, pudiendo suponer incluso la movilización de grandes corrientes migratorias y la modificación de las pautas demográficas. También puede provocar un fuerte desarrollo urbano $\mathrm{y}$, con él, un crecimiento de otros sectores económicos.

Los grandes cambios experimentados en las dos últimas décadas en todos los órdenes, tiene mucho que ver con una situación económica agitada y cambiante, con fuerte impactos en materia social, cultural o ambiental. Esos movimientos influyen también en la alteración de la organización espacial de la actividad económica y de las relaciones existentes entre territorios: junto con viejas regiones industrializadas hoy en declive surgen otras emergentes con mayor atractivo para la inversión empresarial; en el interior de las ciudades y en sus periferias, nuevos espacios de producción, de ocio y consumo provocan una rápida transformación de las estructuras urbanas, al tiempo que el territorio se cubre de densas redes de flujos, tangibles unos y otros intangibles, que favorecen las relaciones entre las personas, las empresas y los lugares.

Uno de los temas que más se están estudiando en la actualidad es todo aquello relacionado con los nuevos espacios industriales basados en las innovaciones 
tecnológicas que se han desarrollado espectacularmente en los últimas décadas dentro de un sistema capitalista global que impregna nuestro día a día.

Estas innovaciones que afectan tanto al cambio tecnológico y a la renovación de los subsectores de actividad industrial, como a la modernización de los subsectores tradicionales, bajo diferentes procesos de innovación que mantienen su competitividad, el lugar más adecuado para su desarrollo son aquellos ámbitos en que existe un denso tejido de pequeñas y medianas empresas (PYMES) especializadas en determinados productos, que han sido capaces de establecer diferentes relaciones de cooperación tanto entre ellas como con el territorio en que se insertan.

Esta industria ha ido creciendo a la vez que se han dado otros procesos como la recesión de regiones tradicionalmente industriales o los procesos emergentes en los países menos desarrollados sobre la base de industrias fuertemente consumidoras de materias primas y de energía. El capitalismo, tanto el de ayer como el de hoy, siempre se ha movido por intereses económicos, en busca del máximo beneficio, y lo seguirá haciendo siempre. No le importará trasladar la producción de su lugar de origen a un país del Tercer Mundo si con ello va a ganar más dinero, no se para a pensar en todas las consecuencias económicas, sociales o medioambientales que sus acciones conllevan.

Cabe destacar las relaciones entre industria y ciudad, ya que la industria se convierte en motor de las transformaciones y del desarrollo, como también el territorio contribuye al despegue de su actividad y de su evolución, esto ha sucedido tanto en los países de vieja tradición industrial como en los nuevos países industrializados o en vías de industrialización cuyo crecimiento de las ciudades es espectacular cosa que conlleva múltiples problemas, tanto de orden urbanístico como social y medioambiental, que repercuten negativamente en el conjunto de la sociedad. Pero los gobiernos de esos países no piensan así, facilitan la implantación de empresas en muchas ocasiones regalándoles los terrenos para que luego sus beneficios sólo repercutan en unos pocos, explotan en muchas ocasiones a los empleados y contaminan todo lo que pueden sin que nadie lo impida, los mandatarios piensan que este es el precio del desarrollo.

Desde siempre la ciudad ha sido el espacio físico más atractivo para la instalación de actividades industriales, tanto por la importancia del mercado como por la oferta de mano de obra en cantidad y calidad. La configuración de economías de aglomeración y de economías de escala explica el crecimiento exponencial de muchas ciudades industrializadas, estas ventajas consisten en el empleo de infraestructuras comunes, equipamientos colectivos, servicios generales. Pero a la vez, algunas deseconomías (conflictos, fricciones sociales, deterioro del entorno e impactos medioambientales) han propiciado también de manera histórica la descentralización de la actividad económica y la difusión de la industria por otros ámbitos que han ofrecido, en cada momento, ventajas comparativas.

Los nuevos modelos organizativos de la producción, surgidos tras la crisis de los años 70 del siglo XX y la revolución tecnológica, han propiciado la consolidación de una economía de alcance mundial y, con ella, una distribución del trabajo también de escala planetaria, posibilitada por el gran avance de los transportes, de las telecomunicaciones y por la rápida difusión de la información, que permiten un exhaustivo control de las fases productivas, en tiempo real, sin demoras y con un abaratamiento de los costes. Así, la fragmentación del trabajo se consolida hoy como el modelo organizativo más 
extendido, y los sistemas industriales se caracterizan por estar formados por complejas redes donde se combinan grandes y pequeñas empresas, fábricas, talleres y trabajo a domicilio, que es posible coordinar gracias a las innovaciones tecnológicas.

La concentración de los recursos minimiza los costes y reduce las incertidumbres; además, en la ciudad tienen lugar los procesos de innovación y de difusión más rápida de la información y se establecen todo tipo de relaciones sociales, al construir un complejo conglomerado de personas, actividades y centros de decisión.

Por todo ello, la ciudad aporta un conjunto de ventajas que hacen de ella, todavía hoy a pesar de los cambios, el entorno más favorable para la aparición de nuevas actividades industriales y, a la vez, para el mantenimiento en general de la actividad industrial.

En ese contexto, el planeamiento urbano puede cobrar una gran importancia, como herramienta capaz de dinamizar la economía local, de apoyar las iniciativas empresariales, de mejorar un entorno urbano hasta convertirlo en espacios atractivos y de innovación, o simplemente en nuevos escenarios donde mejore la calidad de vida de los habitantes. En este sentido, cada vez se demanda más que el planteamiento urbano sea acontecido por la elaboración de planes estratégicos que definan políticas globales, entre las que la regulación del uso del suelo resulta fundamental.

En origen, todo proceso de desarrollo industrial se sustenta en la utilización de una mano de obra abundante y barata, junto con los demás factores productivos. Con la incorporación de cada país al proceso de industrialización, la primera acumulación de capital fue posible por el empleo masivo de la fuerza laboral a bajo precio, circunstancia que todavía hoy se repite en las mismas penosas condiciones en los países del denominado Tercer Mundo. Esos espacios subordinados y subdesarrollados caen ahora en la órbita de un sistema productivo de escala mundial, de la mano de una nueva división espacial del trabajo, que ha llevado hacia esos países las actividades menos cualificadas y con mayor intensidad de trabajo humano.

Por último señalar que el método que he utilizado en este texto es el hipotéticodeductivo, es decir empezar comentando lo general, todo aquello relacionado con definiciones, inicios, características de los parques tecnológicos en el mundo, para posteriormente ir descendiendo de escala, pasando por los proyectos nacionales y el de la Universidad de Alicante, para finalizar en Alcoy, mi ciudad, porque me interesa conocer todos los detalles de este proyectos para poder analizar si tiene un posible desarrollo en la ciudad y como debe de ser para que tenga éxito y alcance los objetivos planteados previamente.

\section{PARQUES CIENTÍFICOS, TECNOLÓGICOS O TECNÓPOLIS}

Uno de los instrumentos con los que se ha trabajado a escala mundial para concentrar, desarrollar y posteriormente difundir tecnología a partir de conocimientos y, por tanto, potenciar los procesos de innovación entre instituciones científicas y las necesidades de los sectores productivos, ha sido la creación de parques científicos y tecnológicos. Primero en los EE.UU., después en Europa y posteriormente en el sudeste asiático. En estos espacios productivos es donde se crean nuevas estructuras científicas y socioeconómicas apoyadas en el conocimiento, en las ideas y en la cooperación entre los entornos institucional, académico y productivo. El antecedente inmediato de los 
parques científicos y tecnológicos lo podemos encontrar en Silicon Valley. Allí, y durante varias décadas, la colaboración entre empresas, organizaciones militares, universidades, departamentos del gobierno norteamericano y entidades financieras de capital riesgo, fueron los agentes imprescindibles para crear un tejido empresarial, social e investigador que posibilitó un rápido avance tecnocientífico. Gracias a esto por los años setenta en Estados Unidos una serie de avances tecnológicos y científicos dieron lugar a grandes innovaciones tecnológicas en los sectores de la electrónica, informática y satélites espaciales. En estas actividades las nuevas empresas creadas y otras ya existentes reorientadas se localizaron en nuevos espacios industriales denominados en principio parques tecnológicos. Fueron tan innovadores que los parques posiblemente no existirían sin la universidad de Stanford que con sus graduados favoreció la implantación de empresas. Así y allí surgió el embrión de las tecnologías de la información y de las telecomunicaciones, que difundidas por el mundo han dado lugar a la aparición de las grandes empresas multinacionales.

Antes que nada cabe nombrar algunas de las definiciones de parque científico y tecnológico de los organismos más representativos de este tipo de proyectos:

Según la Asociación de Parques Científicos y Tecnológicos de España (APTE), se trata de un proyecto, generalmente asociado a un espacio físico, que: $1^{\circ}$ ) Mantiene relaciones formales y operativas con las universidades, centros de investigación y otras instituciones de educación superior. $2^{\circ}$ ) Está diseñado para alentar la formación y el crecimiento de empresas basadas en el conocimiento y de otras organizaciones de alto valor añadido pertenecientes al sector terciario, normalmente residentes en el propio Parque. $3^{\circ}$ ) Posee un organismo estable de gestión que impulsa la transferencia de tecnología y fomenta la innovación entre las empresas y organizaciones usuarias del Parque.

Según la Asociación Internacional de Parques Científicos (IASP), creada en 1984 y con sede en Málaga desde 1996, un Parque Científico es una organización gestionada por profesionales especializados, cuyo objetivo fundamental es incrementar la riqueza de su comunidad promoviendo la cultura de la innovación y la competitividad de las empresas e instituciones generadoras de saber instaladas en el parque o asociadas a él. A tal fin, un Parque Científico estimula y gestiona el flujo de conocimiento y tecnología entre universidades, instituciones de investigación, empresas y mercados; impulsa la creación y el crecimiento de empresas innovadoras mediante mecanismos de incubación y de generación centrífuga (spin-off), y proporciona otros servicios de valor añadido así como espacio e instalaciones de gran calidad.

La terminología que se utiliza para hablar de estos nuevos espacios industriales es muy variada, aunque actualmente la que viene utilizándose con más frecuencia es la de parque científico y tecnológico. La diversa tipología de concentración de actividad innovadora y de "alta tecnología" queda así:

- El parque científico es una iniciativa de base territorial situada en la proximidad de institutos y centros politécnicos superiores o centros de investigación avanzada. Está destinado a estimular la creación y el crecimiento económico basado en el nuevo conocimiento, promoviendo activamente la transferencia de tecnología desde las instituciones académicas y de investigación al tejido y a la organización incluida en el ámbito o extensión del parque. 
La función principal del parque se constituye por las actividades de investigación, desarrollo y planeamiento, concepción de nuevos productos-servicios y el desarrollo de los pasos finales a la fase de comercialización. El trabajo de I+D efectuado por las empresas en el ámbito del parque, a menudo es limitado a la elaboración de prototipos, encauzar la fabricación hacia otros lugares o localizaciones, aunque en algunos casos las empresas comprendidas en los parques científicos manejan excepcionalmente la producción de equipos o sistemas de alta tecnología.

- Un parque de investigación se sitúa normalmente en el entorno de una universidad o de una institución académica o de investigación. Las actividades desarrolladas son principalmente de búsqueda e investigación en lugar de desarrollo, por lo que el elemento característico está constituido por la investigación en actividades de vanguardia científica y tecnológica absoluta.

- Un parque tecnológico comprende empresas centradas en la aplicación comercial de alta tecnología, con actividades comprendidas entre la IDT, producción, venta, asistencia y mantenimiento. El parque tecnológico se distingue de un parque científico o de investigación por la mayor importancia de la actividad de producción, mientras que la participación de instituciones académicas no reviste importancia esencial.

- Un centro de innovación es una estructura destinada a satisfacer la exigencia y necesidades de empresas generalmente nuevas, empeñadas en el desarrollo y en la comercialización de nuevos productos y procedimientos tecnológicos, con relativo alto riesgo de mercado, y la necesidad no sólo de servicios de ayuda y consulta sino también de verdaderas instituciones financieras regionales. El propósito de los centros de innovación es promover la creación de empresas de alta tecnología, sobre todo de pequeña y mediana dimensión. A veces estos centros también son incluidos en proyectos más amplios como los parques científicos o tecnológicos de los que se convierten en parte integrante.

- La incubadora comercial es un centro donde se concentran, en un espacio limitado, empresas de nueva creación. El objetivo es aumentar la posibilidad de desarrollo y la tasa de supervivencia de estas empresas, poniendo a su servicio edificios de carácter modular con servicios de asistencia comunes.

- El parque empresarial o comercial crea un ambiente de calidad a una amplia gama de actividades como la producción más o menos limpia, ensamblaje, venta, exposición y otras actividades administrativas. Algunos parques tecnológicos y científicos que no han tenido éxito en atraer una verdadera y propia clientela científica han pasado a esta categoría.

- También existe el término "distrito tecnológico", "polo tecnológico", "polo o parque científico-tecnológico", e incluso "tecnópolis".

- La tecnópolis es considerada como una entidad limitada espacialmente, es decir, un tipo de ciudad que promueve "en masa" actividades de alta tecnología. Ésta posee una estructura y recursos propios. La tecnópolis no es únicamente un área de actividad para la materia gris y de producción, por el contrario es una verdadera ciudad y propia, que 
ofrece todas las funciones y servicios urbanos típicos como la residencia, educación, recreo, ocio y asistencial.

Los parques científicos, los parques tecnológicos y las tecnópolis comparten tres criterios básicos que además los diferencian de los polígonos industriales y empresariales tradicionales. Los criterios son:

- Calidad y diseño en el espacio físico.

- Requisitos y criterios de selectividad de las actividades, grupos, proyectos y empresas usuarias, especialmente en lo relativo al valor investigador, tecnológico e innovador de las mismas.

- Respeto al medio (industria limpia).

Existe cierto consenso en cuanto a que la categoría parque científico es de menor tamaño y presenta una mayor dependencia de la universidad, así como una clara orientación a la investigación básica y aplicada, y una orientación a la transferencia. Asimismo, un parque científico no suele acoger empresas de tamaño medio o grande en su recinto urbano. Actualmente desde las administraciones, universidades, y demás agentes, existe cierta confusión cuando se plantean proyectos de parques científicos o tecnológicos. Aunque no son términos contrapuestos y pueden complementarse entre sí, su orientación es diferente y ello establece diferencias significativas.

Hoy la ciudad-región se dispersa llegando a saltar los límites administrativos. Desde esta perspectiva de cambios urbanos acelerados, los distritos centrales y los antiguos distritos industriales se readaptan para nuevas actividades y negocios estrechamente relacionados con el cambio tecnológico. Ejemplos los hay a lo largo y ancho del mundo, incluido España y Madrid, donde tanto los gobiernos como compañías privadas de servicios y universidades desarrollan sus proyectos concentrando y reuniendo recursos en torno a campus de formación, investigación o tecnológicos en ciudades que ahora adquieren responsabilidades y funciones nuevas como investigar, innovar, incubar, producir conocimientos, informaciones y contenidos, cultivar una o varias iniciativas de posibles clusters a largo plazo, etc.

Desde la puesta en marcha en 1951 del Stanford Research Parck, el primer proyecto encuadrado dentro de la concepción actual de estos centros, el crecimiento ha sido considerable y sigue siéndolo, según la IASP (Asociación Internacional de Parques Científicos) se ha pasado de contar con 192 parques tecnológicos y científicos en el 2000 a contar en el 2010 con unos 375, concentrando en ellos unas 200.000 empresas. El 59\% de estos parques los encontraremos en Europa.

A partir de la década de los años ochenta del siglo XX se produce una gran proliferación del número de parques en todo el mundo, debido fundamentalmente a la "necesidad de prestigio" e imagen corporativa en el mapa económico regional. Esta tendencia se ralentiza a mediados de los años 90, especialmente en los países que cuentan con un mayor número de parques, y debido al alcance de un punto de saturación en el cual la oferta de espacios interiores en el parque supera la demanda externa.

La iniciativa en la construcción de parques varía de un país a otro. Dentro de los modelos existentes a lo largo del mundo, cabe destacar el modelo anglosajón, pionero en el establecimiento de este tipo de proyectos. En este modelo los parques, más 
vinculados a universidades o a empresas con un alto componente de inversión en $\mathrm{I}+\mathrm{D}$ y recursos propios, son los que lideran el éxito de la creación de empresas, innovación tecnológica en general, y creación de empleos cualificados.

Los parques científicos anglosajones se diseñaron incluyendo a la universidad o incluso desde ésta con el objetivo de autofinanciarse y están íntimamente ligados a sectores tecnológicos emergentes. Así el modelo estadounidense está caracterizado por:

- Un alto protagonismo de I+D.

- Una clara orientación al beneficio, que habitualmente excluye su dependencia de fondos.

- Un alto nivel de innovación y especialización.

Dentro de este modelo de cabría destacar tres parques emblemáticos, que serán el Roure 128, el Research Triangle Park y el Silicon Valley, de los cuales se pueden extraer variables comunes que nos pueden ayudan a explicar el desarrollo de creación de empresas competitivas, sectores emergentes de futuro y nichos de empleo:

- Importancia decisiva de las universidades.

- Interacción entre la universidad e industria.

- Importancia de los servicios de partida.

- Buena respuesta de las autoridades públicas, en ciertos casos con sustanciales apoyos a líneas concretas.

- En muchas ocasiones parten de un planteamiento netamente empresarial.

- Alta consideración de las ventajas relativas a la ubicación, tales como el mercado de trabajo, servicios o accesibilidad.

Pero la realidad va por delante de modelos y definiciones ya sean oficiales o no, y los proyectos de tecnópolis y polos que con denominaciones de científicos y tecnológicos se promueven actualmente combinan diferentes usos y actividades. El concepto de parques tecnológicos aislados que prevaleció antes de los años 90, ha perdido importancia, y está siendo reemplazado por las emergentes comunidades de la innovación o, para otros, del conocimiento, que intentan:

- Estimular la formación y el desarrollo entre múltiples disciplinas, con una alta calidad de vida, aprendizaje continuo e estructuras de organización flexibles.

- Atraer trabajadores con conocimientos y formar agrupamientos industriales dinámicos, en continua evolución, donantes y receptotes de tecnologías.

- Crear foros para el desarrollo de oportunidades económicas y sociales; hacer desaparecer las barreras y lenguajes tradicionales que separan las instituciones formativas de los industriales, los empresarios y la comunidad.

- Crear ciudad-región y ciudadanos del conocimiento. Las ciudades cambian la base económica, innovan y se desarrollan apoyándose en formación y nuevos conocimientos.

Estos proyectos reflejan, cada vez más, los conceptos de compactibilidad, accesibilidad, diversidad y flexibilidad. Infraestructuras y centros tecnopolitanos o empresariales de baja densidad, situados en áreas alejadas de la ciudad central y completamente dependientes del transporte individual, están siendo sustituidos, por la introducción de nuevos modelos urbanos guiados por: 
- Una interacción social entre la enseñanza, formación, fuerza de trabajo y los residentes.

- Creación de un entorno de trabajo con una intensidad capaz de sostener la más amplia y rica combinación de facilidades y servicios de fácil acceso.

- Creación de puestos de trabajo cercanos a los lugares de residencia de los trabajadores.

Existe cierto abandono de la baja densidad y de espacios grandes, expansivos y burocráticos. Las tecnópolis actuales nacen como consecuencia de la transición de la economía industrial a lo que se denomina "economía del conocimiento" en la que los servicios de todo tipo registran elevados porcentajes de empleo, de facturación, y de flujos de información. Son concebidas como equipamientos urbanos de apoyo a la innovación, tecnología, y servicios para las empresas en ellas ubicadas, reforzando su competitividad y mejorando sus prestaciones. Destinadas a la ubicación de ideas, proyectos de empresa o empresas de tecnología avanzada, pretenden constituirse en comunidades de investigación, transferencia de tecnologías y de negocios. Los agentes y empresas integrantes gozan de ventajas añadidas derivadas de la concentración en sus instalaciones de servicios, equipos, laboratorios industriales, personal muy cualificado, etc, que, a su vez, contribuye a la creación de sinergias favorables y a la satisfacción de las necesidades del tejido industrial, de los agentes públicos y privados, de los investigadores, y de la sociedad en general. A su vez, estas nuevas estructuras organizadas suelen actuar como centros de transferencia tecnológica conectando el mundo universitario y empresarial.

En definitiva, las tecnópolis agrupan diferentes instrumentos, redes y agentes para el desarrollo regional, favoreciendo los procesos de I+D+I y la nueva industria. Y, a modo de motores de desarrollo actúan como impulsores y catalizadores de tecnologías, ejerciendo su verdadera influencia en todo un amplio territorio circundante que debe alcanzar la escala regional o metropolitana.

Estos nuevos proyectos reflejan una realidad que no es otra que los cambios en la estructura de las ciudades y las regiones provocadas por la revolución tecnológica y por una economía global. También ha tenido un papel fundamental la aparición de una nueva forma de producción y gestión económica conocida como informacional, que se caracteriza por el hecho de que la productividad y la competitividad se basan en gran parte en la generación de nuevos conocimientos. La economía informacional se caracteriza por nuevas formas organizativas. Las organizaciones horizontales sustituyen a las burocracias verticales como la forma más productiva de organización y gestión. La especialización flexible reemplaza a la producción de masa estandarizada como la nueva forma industrial mejor preparada para adaptarse a una demanda mundial cambiante y a unos valores culturales versátiles. Ello tampoco quiere decir que las empresas pequeñas y medianas sean las formas más productivas de la nueva economía. Las principales compañías multinacionales siguen siendo los centros estratégicos de la economía, así como uno de los principales productores de innovación de la misma. Lo que está cambiando es la forma organizativa, tanto para las grandes compañías como para las pequeñas empresas. La economía informacional es una economía global porque la capacidad generada por las nuevas fuerzas productivas necesita una expansión constante en un mercado mundial dominado por una nueva jerarquía del poder económico, el cual depende de forma decisiva de la información y de la tecnología y que cada vez está menos condicionado por el coste del trabajo y de las materias primas. 
Llama la atención el hecho de que en una economía mundial cuya infraestructura productiva está compuesta de flujos de información, las ciudades y las regiones se están convirtiendo de forma creciente en agentes decisivos del desarrollo económico. Esto es debido precisamente a que la economía es global, los gobiernos nacionales no tienen suficiente poder para actuar sobre los procesos funcionales que conforman sus economías y sus sociedades. Pero las ciudades y las regiones son más flexibles a la hora de adaptarse a las condiciones cambiantes de los mercados, de la tecnología y de la cultura. En realidad, tienen menos poder que los gobiernos nacionales, pero poseen una mayor capacidad de respuesta para generar proyectos de desarrollo con objetivos concretos, para negociar con compañías multinacionales, para fomentar el crecimiento de empresas endógenas pequeñas y medias y para crear las condiciones que atraerán a las nuevas fuentes de riqueza, de poder y de prestigio. En este proceso de generación de nuevos crecimiento, compiten entre sí pero, en la mayoría de casos, esta competición se convierte en una fuente de innovación, de eficiencia, de esfuerzo colectivo por convertirse en un lugar mejor para vivir y más efectivo para los negocios.

En su búsqueda de nuevas fuentes de crecimiento económico y de bienestar social, las ciudades y las regiones se ven estimuladas, tanto positiva como negativamente, por la experiencia internacional comparativa. Muchas zonas que permanecen ancladas en actividades en recesión -sean éstas la fabricación, la agricultura o los servicios del tipo antiguo y no competitivo- se convierten en ruinas industriales, habitadas por trabajadores en paro y dominadas por el descontento social y el deterioro ambiental. Nuevos países y regiones surgen como escenarios prósperos de la nueva ola de innovación e inversión, emergiendo en ocasiones de un profundo atraso agrícola y apareciendo otras en rincones idílicos del mundo que adquieren un dinamismo repentino. Así, Silicon Valley y el Condado de Orange en California; Arizona, Texas y Colorado en la parte occidental de Estados Unidos; Baviera en Alemania; el Midi francés; desde Sofía Antípolis vía Montpellier hasta Toulouse; Silicon Glen, de Escocia; la aglomeración electrónica en Irlanda; los nuevos proyectos del Sur de Europa, desde Bari hasta Málaga y Sevilla; y, sobre todo, los países de reciente industrialización de Asia (Corea del Sur, Taiwan, Hong Kong, Singapur, Malasia) que, en dos décadas, han pasado de ser sociedades agrícolas tradicionales a convertirse en economías altamente competitivas basadas en sectores electrónicos fuertes.

El cambio tecnológico, la internacionalización y la economía avanzan añadiendo actividades nuevas en las ciudades y sus aglomeraciones, lo que constituye un tema mucho más complejo que en etapas anteriores, pues profundizan y modifican las funciones urbanas clásicas. Ante todo esto las empresas se ven obligadas a cambiar sus estrategias y estructuras clásicas, para adaptarlas a un nuevo ritmo lleno de oportunidades. Entre ellas producir la tecnología que vamos a utilizar dentro de diez o doce años que todavía no se ha inventado y que no conocemos dónde surgirá. Tampoco sabemos cuáles y cómo van a ser los productos culturales, formativos y de ocio que han de definir la sociedad de las próximas décadas.

El desarrollo de flujos y relaciones constituyen complementariedades que entrelazan y desembocan en acciones creativas e innovadoras, por lo que el desarrollo adecuado y eficaz de elementos intangibles y sus estructuras organizativas toman una especial importancia en la caracterización y éxito de ciudades y regiones que convierten el conocimiento en riqueza, tecnologías, calidad de vida y bienestar. 
Desde hace años, en los países que crean el cambio tecnológico, existe un acuerdo generalizado en que la investigación y el desarrollo tecnológico se han convertido en la principal fuente de crecimiento. El conocimiento es la fuente de desarrollo en las regiones industrializadas. Las empresas multinacionales juegan un papel importante en el panorama mundial de investigación y desarrollo. Por ejemplo, el fabricante de automóviles estadounidense Ford Motor, invierte ligeramente más en I+D que España, considerando inversión total, es decir, pública y privada.

El papel de las regiones y sus ciudades como epicentros de tales procesos, parece incuestionable. Para bien y para mal, las regiones hoy día, entran en competición directa, de una manera distinta a cómo lo hacían en la etapa anterior, los Estados; es decir, frente al control de las políticas monetarias, del mercado de trabajo, y de los aranceles, es la vía de la competitividad apoyada en inversiones, centros de innovación, tecnologías, conocimientos y formación.

Existe todo un amplio abanico de estructuras, que tienen como objetivo fundamental, por una parte, crear nuevos conocimientos y, por otra transferir adecuadamente los conocimientos y tecnologías al tejido económico y social. Mediante ellas, se quiere potenciar sectores básicos de agricultura e industria, servicios educativos, turísticos y culturales, servicios avanzados que favorecen la creación de empresas de base tecnológica, y el uso de nuevas tecnologías. Además de su incidencia y capacidad de organización industrial, con ellas se pretende, reducir las dependencias tecnológicas, y garantizar el empleo a largo plazo, el empleo no de mañana sino de pasado mañana. Por ello, instituciones y agentes, tienden a implicarse para coordinar un sistema de gobierno en el que, en un contexto de transformaciones económicas y sociales, las actividades científicas, formativas, tecnológicas e industriales, son el bloque a desarrollar en buena parte de las ciudades y regiones que lideran la nueva economía.

Ya hemos visto que no existe una definición única para estos conceptos de carácter urbano y tecnopolitano, pues más bien son hoy en día intereses e intenciones políticas que buscan nuevas estructuras organizativas para promover el cambio sectorial y tecnológico. Las regiones urbanas situadas en los circuitos financieros y económicos mundiales, buscan sustituir las áreas centrales que acogen sectores industriales del siglo XX por una creciente participación en el comercio, en los negocios, en la oferta de parques y servicios avanzados, centros de excelencia y de alta tecnología.

El conjunto de las iniciativas testadas pone de manifiesto la variedad de situaciones existentes, debido principalmente a la mayor o menor densidad de estructuras intermediarias, recursos de capital humano y agentes, así como a su grado de organización, a su uso y conectividad, a la integración y coordinación de actores y diferentes herramientas (centros de I+D, universidades, empresas, administraciones públicas y privadas, redes de agentes, etc), y al mayor o menor grado de implicación y participación.

\section{Los parques tecnológicos y científicos en España}

En España hasta mediados de la década de los años ochenta del siglo XX no existe una preocupación por diseñar un verdadero sistema-red de innovación formado por universidades, centros de servicios técnicos, centros de investigación, empresas y 
medios innovadores. España aparecía como un país despreocupado en aspectos tan importantes como el bajo desarrollo tecnológico de las empresas, la baja formación de los empleados, la escasez de grandes empresas con capacidad de arrastre tecnológico, la falta de mecanismos y programas de innovación coordinados, y la carencia de infraestructuras suficientes para articular el territorio en los nuevos ejes de desarrollo europeo.

Con el fin de "modernizar" la sociedad española, así como resituar las ciudades y los sistemas industriales regionales en la economía global, las propuestas se dirigen fundamentalmente a movilizar los recursos y a crear infraestructuras urbanas de todo tipo. Durante la segunda mitad de los años ochenta, los procesos de reestructuración industrial acometidos, la descentralización administrativa, la creación de un marco autonómico, el ingreso en la CEE, la creciente atracción de capitales financieros, y un mayor conocimiento de la realidad, confluyen para que ciudades $\mathrm{y}$, sobre todo, los gobiernos de las Comunidades Autónomas promovieran políticas favorables al desarrollo regional. Ejemplos de estas medidas son la creación de laboratorios públicos, centros de transferencia de tecnología, y diversas infraestructuras regionales como universidades y centros de investigación.

Pero además el nuevo escenario de Europa provocó la necesidad de ajustar los sistemas productivos regionales a una nueva economía. En esta dirección, para renovar el tejido productivo y reconducir los sectores industriales fordistas hacia sectores de actividad emergentes, uno de los mecanismos ha consistido en ayudas a la industria. Esta política se ha complementado con una oferta de suelo productivo muy flexible desde el punto de vista de la gestión y de las posibles actividades a implantar en nuevos espacios como los parques tecnológicos y científicos, los parques industriales y los parques empresariales.

La proliferación de proyectos en los últimos años no siempre ha ido acompañada de una coordinación con otros aspectos relacionados con la política científico tecnológica Estatal y regional, con la realidad económica, con el tejido empresarial, con la comunidad científica de la región, o con las necesidades de formación técnica, nuevas habilidades y destrezas de la población. La ausencia de una política industrial y tecnológica horizontal, y la competitividad entre CC.AA por la consecución de fondos de la UE han desvirtuado en ocasiones las buenas prácticas en la creación de polos tecnológicos e industriales. Como consecuencia, la eficacia de estas áreas urbanas es muy desigual y muy dependiente del tipo de gestión, enfoque, empresas y centros tecnológicos que están ubicados en ellas.

En España tenemos proyectos expansivos como el de Boecillo, Málaga, los parques industriales del "ocho asturiano", los proyectos industriales en el interior de Galicia, el valle del Txorierri en el que coexiste un doble carácter rural e industrial, etc. Los proyectos de parques en el norte y sur de Madrid, el Campus de la Salud de Granada, ParcBit en Palma de Mallorca, o el gran Área del Vallés, van sustituyendo el escaso ambiente en servicios para la innovación que tenían los primeros proyectos aislados y acotados por un continuo urbano de empresas, centros de innovación, campus universitarios, museos, hoteles, laboratorios industriales, etc., elevando la superficie edificada e incluyendo servicios necesarios para los empleados, técnicos y ciudadanos. En realidad con estas modificaciones consiguen un uso mixto del terreno incorporando una proporción significativa de actividad terciaria, incluso viviendas en algunos proyectos, buscando cierta actividad al margen de la jornada laboral. 
Hoy en España cuando se diseña un parque científico y tecnológico en el contexto de una universidad, se desea cubrir una serie de objetivos, así como no establecer fuertes restricciones a priori sobre el tipo de desarrollo que finalmente se puede llevar a cabo, es decir, se parte más bien de objetivos laxos. Más concretamente, los objetivos perseguidos son:

- Facilitar la transferencia de conocimiento a los sectores productivos y a la sociedad.

- Establecer acuerdos estables a largo plazo con organizaciones empresariales y con las Administraciones Públicas.

- Apoyar la creación de nuevas empresas de base tecnológica ("spin off')

- Dinamizar la creación de nuevos centros de I+D+I propios de la universidad o mixtos con otras entidades.

- Mejorar la visibilidad de la universidad en el entorno regional o nacional.

Cabe destacar que los parques científicos y tecnológicos han aumentado considerablemente en nuestro país en las últimas décadas, sumando en la actualidad un total de 81 proyectos cuando en 1990 sólo eran cuatro, repartidos por la totalidad de las Comunidades Autónomas españolas pero sobre todo los podemos encontrar en algunas de ellas como son Cataluña, Andalucía, Madrid, País Vasco y Comunidad Valenciana. Estas cinco CC.AA. aglutinan el $45 \%$ del total. Destaca especialmente Cataluña con el $16 \%$ pero especialmente dentro de ella la provincia de Barcelona con 18 proyectos de este tipo. A una distancia considerable le sigue Andalucía con un $11 \%$, ya con cifras mucho más modestas encontramos al resto de comunidades.

A finales de 2010, el número de empresas e instituciones instaladas en los parques científicos y tecnológicos de APTE era de 5.539, que acogen a 145.155 trabajadores. El sector que aglutina al mayor número de empresas en los parques miembros de APTE es el de la Información, Informática y Telecomunicaciones con un $23 \%$, seguido por Ingeniería, Consultoría y Asesoría, con el $16 \%$.

En España hay muy pocos proyectos en los que participa activamente el sistema universitario español. La mayoría de las actividades son de tipo comercial, industrial y empresarial.

Cuadro 1. Parques tecnológicos y científicos de España. Año 2011

\begin{tabular}{|c|c|c|c|c|}
\hline \multirow[b]{2}{*}{ CC.AA } & \multicolumn{2}{|r|}{ Socios } & \multicolumn{2}{|c|}{ Afiliados } \\
\hline & Localidad & $\begin{array}{l}\text { Denominación del } \\
\text { Parque }\end{array}$ & Localidad & $\begin{array}{l}\text { Denominación del } \\
\text { Parque }\end{array}$ \\
\hline \multirow[t]{3}{*}{ Andalucía } & $\begin{array}{l}\text { La } \\
\text { Rinconada } \\
\text { (Sevilla) }\end{array}$ & $\begin{array}{lr}\text { Aerópolis, } & \text { Parque } \\
\text { Tecnológico } & \\
\text { Aeroespacial } & \text { de } \\
\text { Andalucía } & \end{array}$ & $\begin{array}{l}\text { Dos Hermanas } \\
\text { (Sevilla) }\end{array}$ & $\begin{array}{lr}\text { Ciudad } & \text { del } \\
\text { Conocimiento. } & \\
\text { Parque } & \text { de } \\
\text { Investigación } & \text { y } \\
\text { Desarrollo } & \text { de } \\
\text { Valme, S.A. } & \end{array}$ \\
\hline & Sevilla & $\begin{array}{l}\text { Parque Científico y } \\
\text { Tecnológico Cartuja } 93\end{array}$ & Córdoba & $\begin{array}{l}\text { Parque Científico - } \\
\text { Tecnológico de } \\
\text { Córdoba S.L. } \\
\text { (Rabanales 21) }\end{array}$ \\
\hline & El Puerto d & Tecnológico & Aljaraque & Parque Científico \\
\hline
\end{tabular}




\begin{tabular}{|c|c|c|c|c|}
\hline & $\begin{array}{l}\text { Santa María } \\
\text { (Cádiz) }\end{array}$ & TecnoBahía & (Huelva) & $\begin{array}{l}\text { Tecnológico de } \\
\text { Huelva S.A. }\end{array}$ \\
\hline & $\begin{array}{l}\text { Jerez de la } \\
\text { Frontera } \\
\text { (Cádiz) }\end{array}$ & $\begin{array}{l}\text { Parque Tecnológico } \\
\text { Agroindustrial de Jerez, } \\
\text { S.A. }\end{array}$ & $\begin{array}{l}\text { Escúzar } \\
\text { (Granada) }\end{array}$ & $\begin{array}{l}\text { Parque } \\
\text { Metropolitano, } \\
\text { Industrial } \\
\text { Tecnológico } \\
\text { Granada }\end{array}$ \\
\hline & $\begin{array}{l}\text { Campanillas } \\
\text { (Málaga) }\end{array}$ & $\begin{array}{l}\text { Parque Tecnológico de } \\
\text { Andalucía }\end{array}$ & $\begin{array}{l}\text { Vélez-Málaga } \\
\text { (Málaga) }\end{array}$ & $\begin{array}{l}\text { Parque } \\
\text { Tecnoalimentario } \\
\text { Costa del Sol - } \\
\text { Axarquía S.A. }\end{array}$ \\
\hline & $\begin{array}{l}\text { Mengíbar } \\
\text { (Jaén) }\end{array}$ & $\begin{array}{lr}\text { GEOLIT, } & \text { Parque } \\
\text { Científico } & \mathrm{y} \\
\text { Tecnológico, S.A } & \end{array}$ & Cádiz & $\begin{array}{l}\text { Universidad de } \\
\text { Cádiz }\end{array}$ \\
\hline & Granada & $\begin{array}{l}\text { Parque Tecnológico de } \\
\text { Ciencias de la Salud de } \\
\text { Málaga }\end{array}$ & & \\
\hline & $\begin{array}{l}\text { La Cañada } \\
\text { de } \quad \text { San } \\
\text { Urbano } \\
\text { (Almería) }\end{array}$ & $\begin{array}{l}\text { Parque Científico- } \\
\text { Tecnológico de } \\
\text { Almería (PITA) S.A }\end{array}$ & & \\
\hline \multirow[t]{3}{*}{ Aragón } & Zaragoza & $\begin{array}{lr}\text { Fundación } & \text { Parque } \\
\text { Científico Tecnológico } \\
\text { Aula Dei }\end{array}$ & Zaragoza & $\begin{array}{l}\text { Fundación Agencia } \\
\text { Aragonesa para la } \\
\text { Investigación y el } \\
\text { Desarrollo } \\
\text { (ARAID) }\end{array}$ \\
\hline & $\begin{array}{l}\text { Cuarte } \\
\text { (Huesca) }\end{array}$ & $\begin{array}{l}\text { Parque Tecnológico } \\
\text { Walqa }\end{array}$ & & \\
\hline & $\begin{array}{l}\text { Alcañiz } \\
\text { (Teruel) }\end{array}$ & $\begin{array}{l}\text { TechnoPark - } \\
\text { Motorland }\end{array}$ & & \\
\hline \multirow[t]{2}{*}{ Asturias } & Llanera & $\begin{array}{l}\text { Parque Tecnológico de } \\
\text { Asturias }\end{array}$ & & \\
\hline & Gijón & $\begin{array}{ll}\text { Parque } & \text { Científico } \\
\text { Tecnológico de Gijón }\end{array}$ & & \\
\hline Baleares & $\begin{array}{l}\text { Palma de } \\
\text { Mallorca }\end{array}$ & $\begin{array}{l}\text { Parque Balear de } \\
\text { Innovación } \\
\text { Tecnológica } \\
\text { (PARCBIT) }\end{array}$ & & \\
\hline \multirow[t]{2}{*}{ Canarias } & $\begin{array}{lr}\text { Las } & \text { Palmas } \\
\text { de } & \text { Gran } \\
\text { Canaria }\end{array}$ & \begin{tabular}{lrr} 
Parque & \multicolumn{2}{r}{ Científico } \\
Tecnológico & de & la \\
Universidad & de & las \\
Palmas de & & Gran \\
Canaria & & \\
\end{tabular} & $\begin{array}{l}\text { Santa Cruz de } \\
\text { Tenerife }\end{array}$ & $\begin{array}{l}\text { Parque Científico y } \\
\text { Tecnológico de } \\
\text { Tenerife, S.A. }\end{array}$ \\
\hline & & & $\begin{array}{l}\text { Puerto del } \\
\text { Rosario } \\
\text { (Fuerteventura) }\end{array}$ & $\begin{array}{l}\text { Parque } \\
\text { Tecnológico de } \\
\text { Fuerteventura }\end{array}$ \\
\hline \multirow[t]{2}{*}{ Cantabria } & Santander & 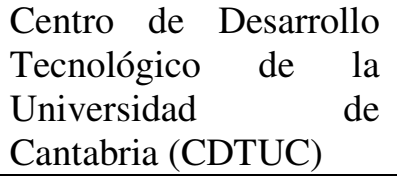 & & \\
\hline & Santander & $\begin{array}{lr}\text { Parque Científico } & \text { y } \\
\text { Tecnológico } & \text { de } \\
\text { Cantabria } & \end{array}$ & & \\
\hline
\end{tabular}




\begin{tabular}{|c|c|c|c|c|}
\hline $\begin{array}{ll}\text { Castilla la } \\
\text { Mancha }\end{array}$ & Albacete & $\begin{array}{lr}\text { Parque Científico } & \text { y } \\
\text { Tecnológico } & \text { de } \\
\text { Albacete } & \end{array}$ & Guadalajara & $\begin{array}{l}\text { Parque Científico y } \\
\text { Tecnológico de } \\
\text { Guadalajara }\end{array}$ \\
\hline \multirow[t]{3}{*}{$\begin{array}{l}\text { Castilla y } \\
\text { León }\end{array}$} & $\begin{array}{l}\text { Burgos, } \\
\text { León y } \\
\text { Boecillo } \\
\text { (Valladolid) }\end{array}$ & \multirow[t]{3}{*}{$\begin{array}{l}\text { Parques Tecnológicos } \\
\text { de Castilla y León }\end{array}$} & Salamanca & $\begin{array}{l}\text { Parque Científico } \\
\text { de la Universidad } \\
\text { de Salamanca }\end{array}$ \\
\hline & & & Burgos & $\begin{array}{l}\text { Parque Científico } \\
\text { Tecnológico de la } \\
\text { Universidad de } \\
\text { Burgos }\end{array}$ \\
\hline & & & Valladolid & $\begin{array}{l}\text { Parque Científico } \\
\text { Universidad de } \\
\text { Valladoli+d }\end{array}$ \\
\hline \multirow[t]{11}{*}{ Cataluña } & Barcelona & 22@Barcelona & Barcelona & $\begin{array}{l}\text { BZ Barcelona } \\
\text { Zona Innovación }\end{array}$ \\
\hline & $\begin{array}{ll}\text { Sant } & \text { Cugat } \\
\text { del } & \text { Vallès } \\
\text { (Barcelona) }\end{array}$ & $\begin{array}{l}\text { ESADECREAPOLIS, } \\
\text { Parque de la } \\
\text { Innovación Empresarial }\end{array}$ & $\begin{array}{ll}\text { Hospitalet de } & \text { Llobregat } \\
\text { (Barcelona) } & \\
\end{array}$ & Consorci Biopol'H \\
\hline & Barcelona & $\begin{array}{ll}\text { Parc } & \text { Científic } \\
\text { Barcelona } & \end{array}$ & $\begin{array}{l}\text { Viladecans } \\
\text { (Barcelona) }\end{array}$ & $\begin{array}{l}\text { Consorci pel } \\
\text { Desenvolupament } \\
\text { del Parc } \\
\text { Empresarial } \\
\text { d'activitats } \\
\text { Aeroespacials i de } \\
\text { la Mobilitat de } \\
\text { Viladecans } \\
\end{array}$ \\
\hline & Lleida & $\begin{array}{ll}\text { Parc Científic } & \text { i } \\
\text { Tecnològic } & \\
\text { Agroalimentari } & \text { de } \\
\text { Lleida } & \\
\end{array}$ & $\begin{array}{l}\text { Sant Adrià de } \\
\text { Besòs } \\
\text { (Barcelona) }\end{array}$ & Fundació b_Tec \\
\hline & Girona & $\begin{array}{l}\text { Parc Científic i } \\
\text { Tecnològic de la } \\
\text { Universitat de Girona }\end{array}$ & $\begin{array}{l}\text { Terrasa } \\
\text { (Barcelona) }\end{array}$ & $\begin{array}{lr}\text { Orbital 40 } & \text { Parc } \\
\text { Científic } & \mathrm{i} \\
\text { Tecnològic } & \mathrm{de} \\
\text { Terrassa } & \\
\end{array}$ \\
\hline & $\begin{array}{l}\text { Cerdanyola } \\
\text { del Vallès } \\
\text { (Barcelona) }\end{array}$ & Parc de Recerca UAB & $\begin{array}{l}\text { Manresa } \\
\text { (Barcelona) }\end{array}$ & $\begin{array}{l}\text { Parc Central - Parc } \\
\text { Tecnològic de la } \\
\text { Catalunya Central }\end{array}$ \\
\hline & $\begin{array}{l}\text { Cerdanyola } \\
\text { del Vallès } \\
\text { (Barcelona) }\end{array}$ & $\begin{array}{l}\text { Parc Tecnològic del } \\
\text { Vallès }\end{array}$ & Barcelona & $\begin{array}{lr}\text { Parc de } & \text { Recerca } \\
\text { Biomèdica } & \text { de } \\
\text { Barcelona } & (\text { PRBB })\end{array}$ \\
\hline & $\begin{array}{l}\text { Mataró } \\
\text { (Barcelona) }\end{array}$ & $\begin{array}{l}\text { Parque Científico y de } \\
\text { la Innovación. } \\
\text { TecnoCampus Mataró- } \\
\text { Maresme }\end{array}$ & Barcelona & $\begin{array}{l}\text { Parc de Recerca } \\
\text { UPF - Ciències } \\
\text { Socials i Humanes }\end{array}$ \\
\hline & Barcelona & Technova Barcelona & Barcelona & $\begin{array}{l}\text { Parc Tecnològic } \\
\text { Barcelona Nord }\end{array}$ \\
\hline & & & Barcelona & $\begin{array}{ll}\text { Parc UPC } & - \\
\text { Universitat } & \\
\text { Politècnica } & \text { de } \\
\text { Catalunya } & \\
\end{array}$ \\
\hline & & & $\begin{array}{l}\text { Reus } \\
\text { (Tarragona) }\end{array}$ & $\begin{array}{lr}\text { Tecnoparc, } & \text { Parc } \\
\text { Tecnòlogic } & \text { del } \\
\text { Camp } & \end{array}$ \\
\hline
\end{tabular}




\begin{tabular}{|c|c|c|c|c|}
\hline \multirow[t]{6}{*}{$\begin{array}{l}\text { Comunidad } \\
\text { Valenciana }\end{array}$} & Valencia & $\begin{array}{l}\text { Ciudad Politécnica } \\
\text { de la Innovación }\end{array}$ & & \\
\hline & Castellón & $\begin{array}{l}\text { espaitec. Parc } \\
\text { Científic, Tecnològic } \\
\text { i Empresarial de la } \\
\text { Universitat Jaume I } \\
\text { de Castelló } \\
\end{array}$ & & \\
\hline & Paterna & $\begin{array}{lr}\text { Parc } & \text { Científic } \\
\text { Universitat } & \text { de } \\
\text { València } & \\
\end{array}$ & & \\
\hline & $\begin{array}{l}\text { San Vicente del } \\
\text { Raspeig }\end{array}$ & \multirow{2}{*}{$\begin{array}{l}\text { Parque Científico de } \\
\text { Alicante } \\
\text { Parque Científico- } \\
\text { Empresarial de la } \\
\text { Universidad Miguel } \\
\text { Hernández de Elche } \\
\end{array}$} & & \\
\hline & Elche & & & \\
\hline & Valencia & \multirow{2}{*}{$\begin{array}{lr}\text { València } & \text { Parc } \\
\text { Tecnològic } & \\
\text { Parque Científico } & \text { y } \\
\text { Tecnológico } & \text { de } \\
\text { Extremadura } & \\
\end{array}$} & & \\
\hline Extremadura & Badajoz & & & \\
\hline \multirow[t]{2}{*}{ Galicia } & $\begin{array}{l}\text { Vigo } \\
\text { (Pontevedra) }\end{array}$ & $\begin{array}{l}\text { Parque Tecnológico } \\
\text { y Logístico de Vigo }\end{array}$ & $\begin{array}{ll}\text { Ferrol } & (\mathrm{La} \\
\text { Coruña) } & \\
\end{array}$ & $\begin{array}{ll}\text { Fundación } & \text { Ferrol } \\
\text { Metrópoli } & \\
\end{array}$ \\
\hline & $\begin{array}{l}\text { San Cibrao das } \\
\text { Viñas } \\
\text { (Ourense) }\end{array}$ & \multirow[t]{2}{*}{$\begin{array}{l}\text { Parque Tecnolóxico } \\
\text { de Galicia }\end{array}$} & & \\
\hline La Rioja & & & Logroño & $\begin{array}{l}\text { Parque Digital de } \\
\text { la Rioja }\end{array}$ \\
\hline \multirow[t]{5}{*}{ Madrid } & Madrid & $\begin{array}{l}\text { La Salle Parque de } \\
\text { Innovación }\end{array}$ & Móstoles & $\begin{array}{l}\text { Móstoles } \\
\text { Tecnológico } \\
\end{array}$ \\
\hline & Leganés & $\begin{array}{l}\text { Parque Científico de } \\
\text { Leganés } \\
\text { Tecnológico } \\
\text { (Universidad Carlos } \\
\text { III de Madrid) } \\
\end{array}$ & Madrid & $\begin{array}{l}\text { Parque } \\
\text { Tecnológico } \\
\text { Ciudad de Madrid }\end{array}$ \\
\hline & Madrid & $\begin{array}{l}\text { Parque Científico de } \\
\text { Madrid }\end{array}$ & Getafe & Tecnogetafe \\
\hline & Madrid & \begin{tabular}{lll}
\multicolumn{2}{l}{ Parque Científico y } \\
Tecnológico de la \\
Universidad \\
Politécnica \\
Madrid
\end{tabular} & & \\
\hline & $\begin{array}{l}\text { Alcalá } \quad \text { de } \\
\text { Henares }\end{array}$ & $\begin{array}{l}\text { TECNOALCALÁ. } \\
\text { Parque Científico - } \\
\text { Tecnológico de la } \\
\text { Universidad } \\
\text { Alcalá }\end{array}$ & & \\
\hline \multirow[t]{2}{*}{ Murcia } & Espinardo & $\begin{array}{l}\text { Fundación Parque } \\
\text { Científico de Murcia }\end{array}$ & & \\
\hline & Fuente Álamo & $\begin{array}{l}\text { Parque Tecnológico } \\
\text { Fuente Álamo S.A. }\end{array}$ & & \\
\hline Navarra & Pamplona & $\begin{array}{ll}\text { Parque de } & \text { la } \\
\text { Innovación } & \text { de } \\
\text { Navarra } & \\
\end{array}$ & & \\
\hline
\end{tabular}




\begin{tabular}{|l|l|l|l|l|}
\hline País Vasco & $\begin{array}{l}\text { Zamudio } \\
\text { (Vizcaya) }\end{array}$ & $\begin{array}{l}\text { Parque Científico y } \\
\text { Tecnológico de } \\
\text { Bizkaia }\end{array}$ & $\begin{array}{l}\text { Oñati } \\
\text { (Guipúzcua) }\end{array}$ & $\begin{array}{l}\text { Oñati, Ciudad } \\
\text { Universitaria y } \\
\text { Tecnológica }\end{array}$ \\
\cline { 2 - 5 } & $\begin{array}{l}\text { Miñano Mayor } \\
\text { (Álava) }\end{array}$ & $\begin{array}{l}\text { Parque Tecnológico } \\
\text { de Álava }\end{array}$ & $\begin{array}{l}\text { Eibar } \\
\text { (Guipúzcua) }\end{array}$ & $\begin{array}{l}\text { Parque } \\
\text { Tecnológico de } \\
\text { Eibar }\end{array}$ \\
\cline { 2 - 5 } & $\begin{array}{l}\text { San Sebastián } \\
\text { (Guipuzcoa) }\end{array}$ & $\begin{array}{l}\text { Parque Tecnológico } \\
\text { de San Sebastián }\end{array}$ & $\begin{array}{l}\text { Ordizia } \\
\text { (Guipúzcoa) }\end{array}$ & $\begin{array}{l}\text { Polo de Innovación } \\
\text { Goierri }\end{array}$ \\
\cline { 2 - 5 } & $\begin{array}{l}\text { Arrasate } \\
\text { (Guipúzcua) }\end{array}$ & $\begin{array}{l}\text { Polo de Innovación } \\
\text { Garaia S.Coop. }\end{array}$ & \multicolumn{2}{|l}{} \\
\hline
\end{tabular}

Fuente: Elaboración propia a partir de los datos extraídos de la APTE.

Cuadro 2. Distribución de los PCyT por Comunidades Autónomas. Año 2011

\begin{tabular}{|c|c|}
\hline CC.AA & \% de PCyT Socios y Asociados de la APTE \\
\hline Cataluña & 16 \\
\hline Andalucía & 11,3 \\
\hline Madrid & 6,4 \\
\hline País Vasco & 5,6 \\
\hline Comunidad Valenciana & 4,8 \\
\hline Otras CC.AA & 55,9 \\
\hline
\end{tabular}

Fuente: Elaboración propia a partir de los datos extraídos de la APTE.

El entorno seleccionado, las infraestructuras, los espacios verdes y las ventajas derivadas de la proximidad a capitales regionales y grandes áreas metropolitanas, emplazan a los parques inicialmente en parajes excelentes. En este aspecto, fueron las primeras infraestructuras de localización industrial en desarrollar una estética novedosa y de alta calidad en un país donde los polígonos industriales se caracterizaban por su abandono y por su escasa calidad. Este hecho ahora tiene menor importancia, pero hace 15 años fue un elemento revolucionario. La idea era mostrar que el desarrollo de la nueva industria, en aquellos años la de las tecnologías de la información, era compatible con la calidad ambiental y arquitectónica.

Como en todo emporio industrial y comercial que ha surgido a lo largo del espacio y del tiempo, hacia ellos y su entorno se dirigen las nuevas inversiones, las empresas avanzadas y la fuerza laboral cualificada. Diseño, infraestructuras y servicios básicos necesarios para el funcionamiento de las empresas caracterizan la mayoría de los parques españoles más consolidados. Existen tres formatos de diseño de parques ubicados en grandes ciudades:

- Los que mantienen amplias áreas verdes.

- Los que son principalmente un conjunto de edificios

- Los que se componen de varios terrenos esparcidos por la ciudad.

Estos tres formatos de parques urbanos no son excluyentes, y se definen en base a los espacios disponibles en cada ciudad. Independientemente del formato, todos los parques contienen amplios espacios verdes y servicios para la interacción social. 
Los parques con áreas verdes suelen mantener hasta un 50\% del terreno reservado para estas áreas, y entre un 33\% y $40 \%$ de un lote para edificación es reservado para paisajismo natural. Los parques compuestos de edificios cuentan con una fácil interacción entre edificios, oficinas e incubadoras. En cada caso, la infraestructura de las edificaciones del parque suelen contar con salas para reuniones, conferencias, convenciones, restaurantes, cafeterías y actividades sociales.

Todos los parques tecnológicos cuentan con servicios como sistemas de telecomunicaciones de alcance mundial y acceso a Internet de banda ancha incorporados en espacios de oficinas y de reunión.

Los parques en España son de grandes dimensiones. Paradójicamente los de mayor superficie se desarrollaron en regiones de bajo desarrollo económico, excepto Zamudio, y como consecuencia en los lugares más desarrollados se hicieron más pequeños. Así ocurrió con la primera fase en el Vallés y en Madrid que fueron los proyectos de menor tamaño y el de Málaga el mayor. Tienen un tamaño medio-grande, en España no hay parque tecnológico con menos de $30 \mathrm{Ha}$. Más del $80 \%$ de los parques en funcionamiento disponen de superficies totales superiores a $50 \mathrm{Ha}$. Por sus dimensiones destacan los proyectos de Valencia, Málaga, Zamudio, Álava y San Sebastián con más de $100 \mathrm{Ha}$. Resumiendo, el $80 \%$ de las regiones que planifican parques, lo hacen en un contexto de bonanza económica y con un objetivo común: parques como instrumentos para apoyar el cambio tecnológico y los procesos de reestructuración industrial.

En los últimos años los procesos de diversificación de actividades y descentralización de tareas que se llevan a cabo en el seno de las grandes firmas, conllevan un tamaño menor de las empresas que se crean. Esta dinámica unida al hecho de que más del $90 \%$ de las empresas españolas son PYMES medidas por el empleo, plantea inicialmente un freno para abrir y posteriormente consolidar procesos de innovación a plazo. Las PYMES no tienen la misma capacidad científica y tecnológica. Sin embargo, las empresas de los parques son vectores claros del cambio industrial, del control de la tecnología, de la innovación y de la renovación tecnológica del sistema productivo.

En cuanto a la localización industrial, en 1997 la IASP realizó una encuesta entre las empresas ubicadas en los parques científicos y tecnológicos de Europa para conocer los motivos por los que dichas empresas se habían establecido en los parques. El primer factor que anotan los empresarios para ubicarse es la imagen y el prestigio que los parques ofrecen a sus empresas. Al parecer una empresa situada en un parque era mejor que si estuviera en un polígono empresarial o industrial y ese efecto se utilizaba como un valor añadido por el empresario para vender más y mejor. El segundo factor por orden de importancia está relacionado con las inversiones y el diferencial en materia de telecomunicaciones que los parques incorporan. Son los servicios que los parques ofrecen $\mathrm{y}$ en particular destacando por encima de todos los demás las telecomunicaciones vía Internet. Queda para el tercer puesto las relaciones con las universidades próximas.

\section{El parque científico de Alicante}

Un ejemplo próximo a la ciudad de Alcoy y que habría que analizar es el Parque Científico de Alicante-Universidad de Alicante. Ubicado junto al campus universitario, 
cuenta con una superficie total de $567.000 \mathrm{~m} 2$. La superficie dedicada a la edificación para los diversos espacios de investigación y funcionamiento será de $170.000 \mathrm{~m} 2$. Actualmente el órgano gestor es el Vicerrectorado de Investigación, Desarrollo e Innovación y la Fundación General de la Universidad de Alicante.

Se concibe como un espacio de excelencia e innovación para incentivar las relaciones empresa-universidad y dinamizar la transferencia de tecnología y la competitividad del sistema económico. El objetivo fundamental es incrementar la riqueza de nuestra comunidad promoviendo la cultura de la innovación y la competitividad de las empresas e instituciones generadoras de saber instaladas en el parque o vinculadas a él.

El modelo de Parque Científico que se propone va asociado a un espacio de convivencia de empresas ya constituidas, empresas nuevas - priorizando las de base tecnológica -, Institutos y grupos de investigación y Laboratorios mixtos de I+D Universidad-, compartiendo servicios logísticos y científico-técnicos de calidad.

Huyendo de un modelo de Parque especializado y ajeno al tejido empresarial de nuestro entorno, se han establecido unos criterios mínimos de incorporación, tales como empresas no contaminantes y estéticamente no rupturistas, de conformidad con los parámetros de contaminación acústica y medioambiental establecidos (gestión de residuos, calidad del aire, tratamiento de aguas,...).

Actualmente se encuentra en fase de construcción. Existen ya tres pequeños edificios construidos y uno más en construcción, además de tres edificios en proyecto. La fecha de finalización de este proyecto es una incógnita dada la nefasta situación económica en la que se encuentra la Comunidad Valenciana y la propia Universidad de Alicante.

\section{La industria en Alcoy y su futuro parque tecnológico}

El término municipal de Alcoy se encuentra en el interior norte de la provincia de Alicante, una zona marcadamente montañosa que tradicionalmente ha limitado el desarrollo de determinadas actividades como agricultura intensiva, comunicaciones, crecimiento urbano racional, suelo urbano e industrial, etc.

Alcoy ha sido hasta hace algunos años la quinta ciudad en población de la Comunidad Valenciana, tras las tres capitales provinciales y Elche. No obstante, desde 1975 en que alcanzara casi los 67.500 habitantes, ha reducido su población de una forma muy destacada hasta los 61.093 actuales (Padrón municipal a 1 de enero de 2011). A ello ha contribuido la crisis de su modelo industrial, basado en gran medida todavía en la industria textil, cuyo origen se remonta al proceso de industrialización endógena que se inició en la segunda mitad del siglo XIX, una industrialización que algunos han calificado de desafío a la geografía (Deffontaines, 1958), dado el peculiar medio físico de la ciudad. También ha tenido mucho que ver su aislamiento de los centros dinámicos valencianos, a causa de una red de carreteras obsoleta y una dinámica urbana pobre, destacando la degradación del centro histórico, declarado Conjunto Histórico-Artístico en 1982. En consecuencia, en los últimos años Alcoy está asistiendo a una preocupante diáspora de industrias y de población hacia municipios cercanos, más atractivos en muchos sentidos. 
Para paliar esta situación se han desarrollado proyectos como la conclusión del tramo de la Autovía Central que atraviesa el término municipal de Alcoy, y que enlaza Alicante con Valencia por el interior. Esta autovía acoge unos 30.000 vehículos diarios ya que se ha convertido, en el poco tiempo que lleva abierta, en la principal vía de conexión entre las dos capitales, al ser la opción más corta, más rápida y sin tener que pagar peaje. Esta nueva vía ha acabado en parte con el tradicional aislamiento de la ciudad, pero no del todo ya que aún sigue padeciendo unas pésimas comunicaciones a través de ferrocarril. A día de hoy el pueblo sigue a la espera de que las administraciones regionales y nacionales se pongan de acuerdo para mejorar la línea que une Alcoy y Valencia, una línea que ha estado durante años olvidada y marginada y que ha estado a punto en varias ocasiones de cerrarse. Por no hablar de la línea que se proyectó a principios del siglo XX para unir Alcoy y la capital de la provincia, llegándose a construir todas las infraestructuras necesarias para ello pero que nunca llegó a circular ningún ferrocarril por las vías. También en su día, allá a finales del siglo XIX existió una línea de ferrocarril que comunicaba Alcoy con el puerto de Gandia. Fue construida especialmente para dar a salida a los productos textiles alcoyanos por el puerto y así llegar a otros países más rápidamente. Con todo esto, queda claro que la ciudad, no ha avanzado, se ha quedado estancada tanto por los problemas internos y la poca actitud de sus políticos como por la poya ayuda recibida desde otras administraciones que se han centrado más en las poblaciones costeras.

Otro proyecto ha sido la recuperación del centro histórico, tanto en su aspecto monumental como residencial, que cabe reconocer que ha mejorado bastante pero en el que aún caben muchas cosas por hacer y que la crisis de la construcción y económica en general se han encargado de paralizar.

El Ayuntamiento local ha buscado una terciarización de la economía alcoyana y ha apostado por el turismo, ya que Alcoy tiene muchos atractivos por explotar desde sus valores naturales, gastronomía, patrimonio o tradiciones. También cabe destacar que en los últimos años se ha pretendido implantar un urbanismo disperso de baja densidad, con proyectos que han sembrado la sociedad de enfrentamientos entre diferentes colectivos, ya que se trata de proyectos como campos de golf y urbanizaciones que afectarían negativamente al medio ambiente y paisaje alcoyano, y que no parece que sea la solución más correcta para sacar a los alcoyanos de la profunda depresión social y económica en la que se ve sumergida desde hace décadas.

Pero sin lugar a dudas el proyecto que más preocupa a los alcoyanos y que no se ha resuelto en las últimas décadas es el tema de suelo industrial. Antes que nada vamos a comentar un poco cual ha sido la problemática de este sector económico en la ciudad.

Los condicionantes actuales para el desarrollo de la industria han cambiado mucho, ya que han perdido fuerza la proximidad a las fuentes de energía y las materias primas, y la han ganado de forma muy importante la facilidad de transporte y la llanura del terreno que permite ofertar suelo barato y con facilidades constructivas. Eso explica la deslocalización geográfica hacia la zona de la Vall d'Albaida, el corredor CocentainaMuro y la Foia de Castalla. Estos municipios ofrecían suelo industrial abundante, de mayor calidad y a menor precio lo que ha conllevado como hemos comentado anteriormente además una pérdida demográfica.

Por otro lado, la aparición de condicionantes actuales como la preservación del medio ambiente y de la salud de la población han añadido más problemas a la industrialización 
alcoyana. Una gran parte del término municipal está protegido por su alto valor medioambiental, está rodeado de dos Parques Naturales, por lo que el espacio disponible para otros usos es muy reducido. Todos sabemos que la industria, como los demás sectores de actividad económica, genera una serie de impactos sobre su entorno, tanto en el desarrollo de su actividad por parte de las empresas, como en las fases previas y posteriores. En este sentido, cabe señalar que hasta hace no muchos años eran habituales los vertidos de los tintes de las fábricas que se asentaban en los cauces de los ríos de la ciudad a sus aguas, por lo que éstas cada día presentaban un color diferente, esto por suerte ha cambiado y ahora las medidas que se toman son mucho más restrictivas. Por esta razón Alcoy debe conservar su patrimonio natural y no ponerlo en riesgo con determinadas agresiones urbanísticas, así podrá ponerlo en valor y aprovecharlo turísticamente.

En la actualidad sigue siendo un gran problema la falta de suelo industrial, a pesar de que también es cierto que debido a la crisis tan intensa que estamos sufriendo toda actividad económica está paralizada y ahora mismo no se implantarían empresas pero se espera que en unos años está situación haya mejorado, hayamos hecho los deberes y tengamos las instalaciones necesarias para impulsar el desarrollo empresarial y económico en la ciudad.

Las dos zonas con más posibilidades topográficas de instalación del espacio industrial son la Vall de Polop y la Canal. De este modo, por ser una gran superficie topográficamente llana y por la proximidad a una autovía clave como nudo de comunicaciones (Autovía Central Valenciana-A7-), se pensaba que el emplazamiento idóneo para una nueva zona industrial era la Canal, al sur del término municipal, clasificada como Suelo No Urbanizable de Protección Especial Forestal y Paisajística por el Plan General de Ordenación Urbana (PGOU) de 1989.

Este proyecto salió a la luz en 1995 de la mano del por aquel entonces alcalde Josep Sanus del Partido Socialista Obrero Español (PSOE) e iba a contar con una superficie de un millón de metros cuadrados. Se trata de un proyecto fantasma que ha estado defendido por los diferentes partidos políticos que han gobernado en la ciudad en los últimos 15 años pero que no ha avanzado en ningún momento al encontrase en su camino multitud de inconvenientes. Llama la atención que el partido político que en un principio defendió su construcción, en el momento en que quedaron relegados a la oposición en el 2000, se posicionaran totalmente en contra de él durante los 10 años de gobierno del Partido Popular (PP), los mismos que en 1995 también se opusieron a este proyecto. Durante ese tiempo, al igual que el resto de partidos de la oposición, se han posicionado en el lado de los grupos ecologistas de la comarca que siempre han defendido que está no era una buena opción debido a los grandes impactos negativos medioambientales que podía generar a su entorno más próximo. La principal amenaza de este proyecto es que supondría un grave peligro de contaminación del acuífero del Molinar, principal (e insustituible) fuente de abastecimiento de agua potable de la ciudad. Todos los estudios realizados sobre la zona confirman la alta vulnerabilidad de este acuífero, cuya contaminación tendría unas consecuencias sanitarias, ambientales y económicas catastróficas. Es más, los estudios más profundos realizados demuestran que si se construye no existen medidas preventivas suficientes que puedan garantizar a medio y largo plazo la seguridad del acuífero, por muy cuidadosa que sea la actuación de los responsables (que no es el caso habitual). 
Dicho proyecto en un principio se trataba de un simple polígono industrial pero a raíz de estas complicaciones acarreadas por la alta calidad ambiental de esta zona se fue transformando en un moderno parque tecnológico, exquisitamente respetuosos con el entorno y el cual nos iba a sacar de esta profunda depresión, clave para el crecimiento económico de la ciudad y el futuro de nuestros hijos. Pero como ya hemos dicho, este proyecto no ha avanzado en ningún momento, por la fuerte oposición política local y de una parte de la sociedad alcoyana así como de algunos organismos como la Confederación Hidrográfica del Júcar. Así hemos llegado hasta hoy, han pasado muchos años y los políticos nos han engañado defendiendo lo indefendible, en mayo de 2011 se produjo un cambió en el gobierno local, a pesar de volver ha ganar las elecciones el PP perdió muchos votos, en gran parte por todos estos proyectos fallidos, dando lugar a la formación de un tripartito de izquierdas (PSOE, BLOC e Izquierda Unida). Este nuevo gobierno parece que ha enterrado definitivamente el conflictivo parque tecnológico de la Canal y apuesta por nuevas ideas en materia industrial que son las siguientes:

- Parque tecnológico urbano: Ya que en la periferia no existe una zona apropiada que reúna las características para este tipo de proyectos, se ha pensado que una posible alternativa es instalarlo en el centro urbano. Según afirman uno de los primeros pasos será solicitar la integración en la Asociación de Parques Científicos y Tecnológicos de España, para más tarde, siempre de la mano de la Universidad Politécnica de Valencia, la Cámara de Comercio y del resto de empresarios y entidades sociales decidir cuál es la ubicación ideal y en una segunda fase buscar la financiación necesaria. Las instalaciones se pretende que alberguen centro de negocios y de nuevas tecnologías. Entre las posibles ubicaciones que se barajan, cobran fuerza la antigua fundición Rodes o los alrededores del campus de la Universidad Politécnica de Valencia. Se pretende que sea un parque tecnológico de pequeñas dimensiones, a diferencia de lo que es habitual (convirtiéndose en más pequeño del país con total seguridad), con empresas de base tecnológica y no contaminantes, que no necesiten unas buenas comunicaciones.

El tema de la financiación para su construcción es uno de los mayores problemas ahora mismo, ya que nos encontramos en una situación económica muy complicada en la que todas las administraciones están en déficit y no tienen dinero para grandes proyectos. Es en estos momentos de continuos recortes cuando piensas en los millones de euros que tanto la administración local como la regional ha despilfarrado en los últimos de años de bonanza económica cuando se pensaba que nunca volveríamos a una crisis tan fuerte como la actual. Una de las posibles vías sería pedir ayudas a la UE que siempre muestra interés en este tipo de proyectos.

Este parque tecnológico urbano tendría sus ventajas ya que no atenta contra el modelo de ciudad tradicional, contra los hábitos y comportamientos ciudadanos propios de nuestras ciudades. Es decir no favorece una disgregación espacial de funciones ni provoca los desplazamientos cotidianos masivos al lugar de trabajo como hacen los espacios industriales situadas en las periferias de las ciudades, donde el vehículo privado se hace indispensable, en este caso se favorecería la movilidad a pie y el transporte pública contribuyendo a una ser una ciudad más respetuosa con el medio ambiente. Otro de los puntos favorables que puede contar este tipo de instalación en la ciudad es la presencia de una mano de obra cualificada debido a la larga tradición industrial y un sentido pionero en los empresarios que marcó el proceso de 
industrialización. Lo que es evidente es que la relación entre la Escuela Politécnica Superior de Alcoy (EPSA) perteneciente a la Universidad Politécnica de Valencia y los empresarios debe de ser totalmente fluida, para que el trasvase de conocimientos sea efectivo y se puedan aplicar posteriormente en las empresas. Para ello también es imprescindible que estén presentes otros agentes importantes de la ciudad como la Cámara de Comercio, el Centro Europeo de Empresas Innovadoras de Alcoy así como otras administraciones como la local, regional o nacional. Es el único camino para que el proyecto alcance el éxito que todos esperamos y se convierta en uno de los revulsivos que cree puestos de trabajo y reactive la malherida economía local.

- Polígono industrial mancomunado: Después de muchos años dando la espalda al resto de municipios de la comarca, por fin se han dado cuenta que lo mejor es ayudarse entre todos que así les será más fácil progresar económicamente, todos se necesitan para llevar a cabo determinados proyectos, uno de ellos puede ser un polígono industrial mancomunado. Esta idea surge a raíz del proyecto de formación de mancomunidad que pretende aglutinar al mayor número de municipios de las comarcas de L'Alcoià i el Comtat, un proyecto que después de muchos años reclamando su puesta en marcha se inició en los últimos años del anterior gobierno del PP y que ya está en los últimos pasos para su formación definitiva contando con 15 municipios. Sería en este polígono donde se instalarían las grandes empresas que necesitan parcelas de mayor tamaño y que se dedican a actividades más contaminantes y necesitan unas buenas comunicaciones a pie de autovía. Por lo tanto se busca un emplazamiento a pie de autovía en término municipal de Muro o Cocentaina que sí disponen de suelo necesario para este fin. Cabría resolver una cuestión de gran relevancia que no es otra que como se repartirían los costes de la construcción y los impuestos los municipios implicados. Muchas de las empresas que se instalen en este futuro polígono continuarán siendo textiles, la clave para que puedan salir de la crisis en la que se ve asumida esta industria desde hace años, pasa por el desarrollo de nuevos textiles técnicos que sean de aplicación en la protección personal, la automoción y el transporte de viajeros, la construcción y la arquitectura, el deporte, el embalaje, los higiénicos y sanitarios y de uso industrial, entre otros. Se trata de generar nuevos productos especializados con un elevado valor añadido que permitan acceder a una serie de mercados emergentes para la actividad textil. Para ello es fundamental el papel del Instituto Tecnológico del Textil situado en Alcoy, un centro tecnológico dedicado a la investigación de los ámbitos de conocimiento de la ciencia y la tecnología que tengan aplicación en la industria textil. AITEX es una asociación privada sin ánimo de lucro, integrada por empresas textiles y afines, cuyo objetivo principal es mejorar la competitividad del sector y ofrecer a la sociedad soluciones de base textil que contribuyan a mejorar el bienestar, la salud y la calidad de vida de las personas.

- Aprovechar las numerosas naves vacías en los polígonos industriales ya existentes: En la actualidad Alcoy cuenta con 400.000 metros cuadrados de suelo industrial repartidos en diferentes polígonos industriales. Una posible solución sería llevar adelante un plan para vender o alquilar las numerosas naves sin uso a gente joven con buenas ideas pero que se encuentran con la dificultad de la falta y elevado precio de la oferta disponible en materia industrial. También es verdad que estas zonas industriales cuentan con numerosos problemas que arrastran desde el momento de su construcción, los encontramos en zonas con una importante pendiente con los inconvenientes que ello acarrea para el buen funcionamiento de estas actividades. Por ello su construcción es costosa y el precio del suelo será elevado lo que a la hora de implantarse las empresas 
les hará buscar otras opciones más económicas en municipios cercanos. Además estas zonas industriales en ocasiones están demasiado cerca de las zonas urbanas y deben tender a eliminarse en la mayoría de los casos por razones de salubridad o puramente técnicas (tráfico, proximidad a los ríos, etc). En los últimos años han sido constantes los brotes de legionella, la famosa bacteria que ya es uno más de los habitantes de este municipio, ya que no hay año que no se oiga hablar de ella y de los numeroso afectados que deja a su paso, en ocasiones incluso deja víctimas mortales en su mayoría personas de avanzada edad y con otras patologías asociadas. Las causa de esta bacteria después de años y años aún son un tanto desconocidas, en un primer momento se culpó de su existencia a las torres de refrigeración de las industrias y desde entonces (1999) pasan controles exhaustivos, como medidas para acabar con ella se llevó a cabo una hipercloración del agua y se cerraron todos los surtidores y estanques de la ciudad, y en los últimos tiempo se ha encontrado rastro de ella en los lavadores de coche y en las máquinas de asfaltar las calles. Esta bacteria ha sido una de las causas por los que desde el gobierno local ha promovido el traslado de las tradicionales industrias de los cauces de los ríos a los polígonos industriales de los alrededores. En definitiva, otro de los problemas que Alcoy sigue sin saber resolver.

En la actualidad, las nuevas estrategias urbanas, después de alentar el proceso de terciarización de las economías locales, han puesto freno a esa creciente especialización y proponen mantener y revitalizar la actividad industrial, en el seno de políticas integrales, que defienden la base industrial para no depender exclusivamente del sector servicios y por lo beneficios efectos sociales generados por la industria, que atañen a una mayor cohesión social, a la generación de empleo y a la incentivación del sector servicios, tanto de investigación y asesoramiento para las empresas, como por la propia demanda de los trabajadores industriales. Es por esta razón por la que es de gran importancia volver a potenciar el sector industrial en la ciudad, tanto el textil como otros nuevos sectores, y así recuperar el esplendor empresarial de la historia de Alcoy y construir un modelo de ciudad con perspectivas de futuro y que sea capaz de liderar el desarrollo socioeconómico de las comarcas del interior.

\section{CONCLUSIÓN}

Normalmente el desarrollo de los parques en el tiempo es largo. A veces hay que rediseñar objetivos, replantear y modificar etapas o reasignar recursos. Un factor desestabilizador e incluso desactivador de los proyectos son los cambios políticos que pueden desviar o aparcar transitoria o definitivamente el parque.

La mayoría de las iniciativas españolas se han quedado a medio camino de lo que pretendían ser en sus comienzos. El modelo se ha repetido por ciudades y ciudadesregiones sin abordar conexiones con el tejido industrial y las universidades. Este es uno de los principales peligros que puede correr el proyecto en Alcoy, por eso es vital que una vez por todas los agentes de la sociedad alcoyana (administraciones, universidad, instituciones económicas y empresarios de la ciudad) se pongan de acuerdo.

De las nuevas iniciativas lanzadas muy recientemente, que ya surgen con la etiqueta de "parque científico" se puede decir que es importante una gestión basada en Órganos (presencia de Universidades, Fundaciones, Asociaciones, Consorcios, Administración...) sin ánimo de lucro que defiendan los intereses y objetivos generales 
que concurren en un parque tecnológico o científico. Formulas como las de las fundaciones permiten dotar de representatividad y animo no lucrativo la gestión y toma de decisiones.

Los proyectos de parques tecnológicos que mejor han funcionado se instalaron en amplias zonas periféricas sin problemas a corto plazo de saturación urbana (Boecillo, Zamudio-Erandio, Tres Cantos, Miñano en Álava, PT de Málaga, etc.).

En Alcoy, la escasez y limitación física del espacio, condiciona el tamaño y el crecimiento de a las empresas a instalar, además impide que se desarrollen determinado tipo de actividades de investigación, que pueden considerarse peligrosas $\mathrm{o}$ contaminantes. A esto se añade que el suelo urbano es caro y es una variable que habrá que vigilar en el caso del parque tecnológico urbano si se desea atraer a empresas frente a otras ofertas de suelo más barato.

Se trata de vigilar todos los aspectos de la interacción entre el nuevo proyecto de futura tecnópolis y el entorno territorial donde se ubique. Los proyectos han iniciado su andadura con fuerte apoyo de los gobiernos regionales y, en principio, atrayendo grandes empresas a las instalaciones del parque tecnológico. Actualmente, un proyecto nuevo de calado regional requiere otros planteamientos para no derivarlo sólo hacia un parque empresarial o tecnológico donde se instalan simplemente empresas y centros tecnológicos independientes. La tendencia es hacia el parque científico tecnológico capaz de aglutinar disciplinas, centros, equipamientos, consorcios, plataformas, etc., y que se diferencia precisamente por su fuerte conexión con la universidad y la ciudad y por lo servicios científico-tecnológicos concretos y específicos, pero de muy alto valor, que aporta al conjunto del tejido económico y social.

Los parques de éxito analizados en España han combinado efectivamente la relocalización de empresas, y la venta de parcelas actualmente de tamaños mediopequeños con el alquiler de edificios para oficinas e incubación.

No se sabe a ciencia cierta si invirtiendo más en I+D aseguramos el desarrollo regional. Pero lo que sí sabemos es que si no invertimos más en I+D no aseguramos tecnología y empleos cualificados. Estamos ante el reto de crear nuevas estructuras organizativas capaces de optimizar y elevar la productividad. Para que estas áreas urbanas deriven en tecnópolis han de conseguir fuerte componente universitario investigador que genere nuevos conocimientos, estar integrados en el mundo empresarial, y que exista en el inicio cierto compromiso de la Administración. Sin embargo, la política industrial ha consistido en proveer infraestructura urbana hasta el punto que conviene racionalizar parques tecnológicos, científicos y demás: sin tejido industrial, sin ideas, sin proyectos universitarios, sin masa crítica,...las tecnópolis y las redes de investigación no producen los resultados esperados en las economías regionales.

Cabe destacar que si bien podemos hablar de éxitos también se detectan irregulares resultados. Los motivos de este fracaso son variados, pero lo que se observa es una incorrecta política en el campo de la innovación. Es posible mejorar corrigiendo planteamientos iniciales y sobre todo planificando parques científico-tecnológico, no polígonos industriales, sin mimetismos. Es difícil incluir proyectos como el de Galicia, Asturias, Walqua, Geolit, Rabanales, ParcBit, Tres Cantos,etc., como parques 
científicos, pues más bien se trata de parques empresariales o viveros d empresas que pueden ser promovidos por Ayuntamientos e instituciones privadas.

Los medios de innovación territorialmente concentrados en torno a ciudades dinámicas, son lo que constituyen las fuentes de riqueza en la nueva economía. Para ello, resulta fundamental la relación entre ciudad y universidad. Las universidades son un motor de crecimiento económico, tecnológico y empresarial, pero también son un factor de creación de ciudad. Actualmente, la universidad es un elemento esencial de dinamización para el tejido urbano e industrial, a la vez que de la producción de mano de obra cualificada.

La innovación y el desarrollo tecnológico no es sólo cuestión de parques tecnológicos y de investigación. Éstos son instrumentos y no un fin en sí mismo. También consiste en la vida urbana diaria que es lo que atrae a la juventud, a los innovadores y a los ingenieros a las ciudades y regiones. Calidad de vida, oferta cultural amplia y diversificada y ocio también son vectores favorables. Toda ciudad y área metropolitana importante contiene lugares de encuentro virtuales y materiales en los que chocan mundos diferentes. De este cruce se obtiene un estilo de vida que acaba activando y estimulando los procesos de innovación.

La creciente conciencia social de respeto por el medio ambiente de los últimos años ha hecho que se centren más esfuerzos en la búsqueda de un desarrollo sostenible. Cabe potenciar una industria eco-competitiva, en línea con el concepto de crecimiento sostenible, al tiempo que se apuntaban las grandes dificultades que experimentan las empresas que siguen esa orientación, especialmente derivadas de la rentabilidad a corto plazo y del escaso apoyo desde las administraciones públicas. Por ello es necesario que desde los respectivos países aumenten su presupuesto destinado a proyectos de I+D+I ya que ahí es donde puede residir su futuro progreso y una mayor calidad de vida de sus habitantes.

Ahora bien, la realidad no es tan sencilla y las dificultades encontradas en la puesta en marcha de proyectos específicos de las universidades proceden tanto de la dificultad en asegurar un compromiso de las Administraciones con su desarrollo, como del nuevo regionalismo que en ocasiones copia modelos no adaptados a las necesidades, fortalezas y debilidades de la ciudad-región o de universidades concretas y su entorno. La inexperiencia en estos espacios y equipamientos que suelen comenzar por desarrollos urbanos e inmobiliarios, es otro de los problemas para afrontar con éxito proyectos que por encima de optimizar recursos de equipamientos científicos, financiación de la investigación, investigadores, masa crítica, etc., operan con recursos virtuales en esquemas y modelos organizativos que poco han cambiado en las últimas décadas.

Ante esto, surge una pregunta ¿todas las ciudades y universidades deben de apostar por parques científicos/tecnológicos? Lo que sí hay que tener claro es:

1. Definir objetivos y estrategias claras a medio o largo plazo: ¿hacia dónde va la ciudad, qué quiere ser y ofrecer?

2. Adaptar la estrategia de desarrollo de los proyectos y programas tecnopolitanos a las peculiaridades de las ciudades-regiones.

3. Aprovechar sus fortalezas para crear complementariedades con otras regiones y ciudades. 
Los parques tecnológicos/científicos no son la solución a todos los males que vemos en las ciudades de hoy en día, pero sí pueden ser el motor que impulse de nuevo el crecimiento de determinadas ciudades o regiones, para ello como hemos visto se tienen que dar determinadas condiciones. Tan importante como esto es mantener el resto de actividades económicas, especialmente aquellas relacionadas con la conservación del medio rural y natural como pueda ser la agricultura, ya que si no se hace el día de mañana ya no tendrá solución.

\section{BIBLIOGRAFÍA}

Asociación de Geógrafos Españoles. Colegio de Geógrafos de España. Universidad de Alicante. Paisajes y Geografía en tierras alicantina, Alicante 2011, pp.15-74.

CASTELLS, M. Tecnópolis del mundo: la formación de los complejos industriales del siglo XXI. Madrid: Alianza, 1994.

MARTÍNEZ PUCHE, A y PÉREZ PÉREZ, D. El patrimonio industrial de la provincia de Alicante. Rehabilitación y nuevos usos. Alicante: Publicaciones de la Universidad de Alicante, 2001.

ONDATEGUI, J. C. Las tecnópolis en España. Madrid: Aranzadi, 2008.

PÉREZ, D. Reestructuració dels espais industrials de l'eix Alcoi-Cocentaina-Muro. Alicante: Instituto Alicantino de Cultura "Juan Gil-Albert”, 1997.

VALERO ESCANDELL, J. R. y PONCE HERRERO, G. En SEGRELLES SERRANO, J. A. (Dir.). Geografía humana: fundamentos, métodos y conceptos. Alicante: Editorial Club Universitario, 2002, pp. 151-190.

TORMO i SANTONJA, J. Mariola: sistema productivo y estrategia territorial. Alicante: Publicaciones de la Universidad de Alicante, 2011.

\section{RECURSOS ELECTRÓNICOS}

Asociación de Parques Científicos y Tecnológicos de España (APTE)

$<$ http://www.apte.org/es/>. [Consulta: 14 de diciembre de 2011].

Cámara de Comercio de Alcoy

$<$ http://www.camaraalcoy.net/ficheros/planestrategico.pdf $>$. [Consulta: 16 de diciembre de 2011].

IRIBAS, J. M. Diagnóstico de las funciones urbanas de Alcoy: Conclusiones y propuestas

<http://sue.camarascv.org/administracion/adjuntos/DAFO_ALCOY.pdf>. [Consulta: 3 de enero de 2012]. 
Organismo dependiente de la Comunidad de Madrid encargado de ofrecer servicios de innovación tecnológica, investigación y desarrollo.

$<$ http://www.madrimasd.org/informacionidi/biblioteca/publicacion/doc/ParquesCientifi cosTecnologicos.pdf>. [Consulta: 14 de diciembre de 2011].

Parque científico de la Universidad de Alicante

$<$ http://www.uaparc.org/>. [Consulta: 28 de diciembre de 2011].

TORMO i SANTONJA, J. Tendencias actuales del sector industrial en la comarca `El Comtat' (Alicante)

$<$ http://rua.ua.es/dspace/bitstream/10045/13414/1/XXXX_Jordi_11.pdf >. [Consulta: 3 de enero de 2012].

(C) Copyright José Vicente Ibáñez Llácer, 2013.

(C) Copyright GeoGraphos, 2013.

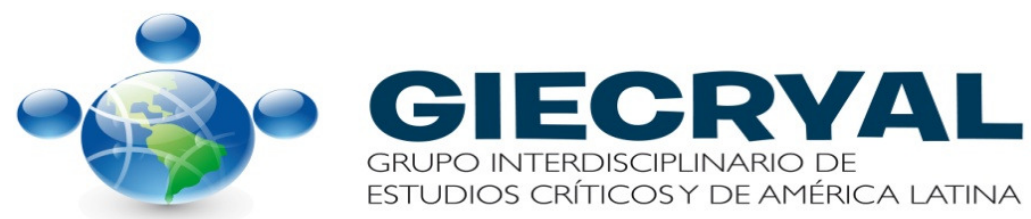

